\title{
An Investigation on Morphology and Fractal Dimension of Diesel and Diesel-Biodiesel Soot Agglomerates
}

\author{
Aline L. N. Guarieiro, ${ }^{a}$ Arantzazu Eiguren-Fernandez, ${ }^{b, c}$ Gisele O. da Rocha ${ }^{a, d, e}$ and \\ Jailson B. de Andrade ${ }^{*, a, d, e}$
}

aINCT em Energia e Ambiente, UFBA, 40170-290 Salvador-BA, Brazil

${ }^{b}$ Department of Environmental Health Safety, University of California, Los Angeles-CA, USA

cAerosol Dynamics, Inc., 935 Grayson St. Berkeley, 94710 Berkeley-CA, USA

'Instituto de Química, Universidade Federal da Bahia, 40170-290 Salvador-BA, Brazil

${ }^{e}$ Centro Interdisciplinar em Energia e Ambiente (CIEnAm), Universidade Federal da Bahia, 40110-040 Salvador-BA, Brazil

\begin{abstract}
In this study, it is reported the fractal dimension and morphology of ultrafine particles emitted by a diesel engine run with B4, B50, and B100. Transmission electron micrographs evidenced two main groups of particles with characteristic and distinct morphological behaviors: (i) particle agglomerate structures self-organized within a fractal-like geometry, and (ii) amorphous and irregular particles with diffuse edges in a liquid-like particle appearance, mainly associated with some sub-fractions of samples collected from B50 and B100 combustion. Particles from ( $i$ ) showed typical diesel soot morphology and fractal dimension. Primary particle diameter $\left(D_{\mathrm{pp}}\right)$ was $24 \pm 4 \mathrm{~nm}, 23 \pm 4 \mathrm{~nm}$, and $20 \pm 4 \mathrm{~nm}$ for B4, B50, and B100, respectively. Mean aggregate gyration diameters $\left(\mathrm{D}_{\mathrm{g}}\right)$ ranged from $242 \pm 140 \mathrm{~nm}$ for B4, $210 \pm 135 \mathrm{~nm}$ for B50, and to $232 \pm 140 \mathrm{~nm}$ for B100. In turn, fractal dimensions $\left(\mathrm{D}_{\mathrm{f}}\right)$ were 1.94, 1.89, and 1.99 for B4, B50, and B100, respectively. On the other hand, particle from (ii) had their morphology impaired from the addition of biodiesel to petrodiesel in a way it did not follow a fractal geometry.
\end{abstract}

Keywords: nanoparticles, morphology, fractal dimension, biodiesel/diesel emissions, soot agglomerates

\section{Introduction}

Diesel engines are largely used in both stationary and mobile applications whenever is needed a high-power source. ${ }^{1,2}$ They provide high thermal efficiency, and consume relatively cheap fuel. ${ }^{2}$ However, diesel engines emit a large amount of harmful particulate matter (PM), which is associated with adverse health-related outcomes. ${ }^{3}$ Diesel engine exhaust is a complex multi-mixture of diverse pollutants found either in vapor- or in particle-phases. Examples of them are ultrafine particles (UFP, particle diameter $\left.\left(\mathrm{d}_{\mathrm{p}}\right)<100 \mathrm{~nm}\right)$ or nanoparticles $\left(\mathrm{NP}, \mathrm{d}_{\mathrm{p}}<50 \mathrm{~nm}\right)$, organic carbon (OC), and elemental carbon (EC) as well as volatile and/or semi-volatile organic compounds (VOC and/or SVOC).$^{4-9}$ Exposure to traffic-related air pollutants has been linked to health effects by epidemiological

*e-mail: jailsong@ufba.br studies., ${ }^{3,10,11}$ Some of them have specifically supported the adverse health effects of exposure to UFP and NP in addition to fine and/or coarse particulate matter. ${ }^{12}$ Health problems include increased risk of reduced lung function, adverse respiratory symptoms, asthma, cardiovascular diseases, morbidity, and mortality. ${ }^{3,10-15}$

Diesel engine exhaust particles are very complex geometrically, being mainly composed by black carbon/ soot. They are principally formed during combustion in the fuel rich regime of a combustion chamber. ${ }^{16-19}$ Diesel carbonaceous soot aggregates consist of many spherical monomers ranging from $20-50 \mathrm{~nm}$ in diameter composed of graphite carbon typically coated with organics. Those aggregates are fractal agglomerates of solid primary nanoparticles. ${ }^{5,16-18,20-22}$ The aggregates have mobility diameter in the ultrafine range and are frequently referred to either as 'elemental' carbon (EC) or 'black' carbon (BC), depending on whether the context is chemical or optical, 
respectively. ${ }^{21,23}$ The morphology of soot determines their properties, their effect in the environment and how it can significantly affect their deposition in human respiratory system $^{20,23}$ since it may affect the way particles interact with lung epithelial cells. ${ }^{24}$ Typical morphologies are regarded as aggregates, spheres, irregularly shaped, and/or barshaped particles. ${ }^{24,25}$ The size, structure, composition and concentration of aggregate particles is normally modified by engine types, type and quality of fuel burned as well as operating conditions, such as load, speed, combustion temperature, air-to-fuel ratio, and injection pressure, among others. ${ }^{16,26}$

Furthermore, not only to determine the NP and UFP morphology but also the measurement of their size are important points to be addressed. Since the smaller the particle is the bigger is the surface area, having a higher probability to suffer modification in the composition, by absorbing/adsorbing fractions of potentially toxic organic compounds. In this way, it is related to the ability of participating in atmospheric chemistry as well as worsening possible health-related injuries. Additionally, the smaller the particle is the deeper it may go in the respiratory system and possibly higher would be the related health problems. ${ }^{1,3}$

In urban areas, carbonaceous particulate matter typically accounts for $25-50 \%$ of the ambient $\mathrm{PM}_{2.5}$ besides having a significant impact on the global climate, either scattering or absorbing light. Soot particles are ubiquitous in the atmosphere and are generated by internal combustion engines, among other combustion sources. Despite its relevance, to date only few studies consider the actual ultrafine particle morphologies and further investigations to better understand the role of the particle shape in the atmosphere and how it contributes to some health effects still are necessary.

In spite the fact the recent advances in reducing diesel emitted particles by improving engine technologies, diesel engines still exhaust a relatively high concentration of NP and UFP to the atmosphere, which rise both relevant environmental and human health concerns. In the same way, it has been applied another alternative strategy to improve diesel emission quality, which is the partial replacing of fossil diesel by biodiesel. The use of biodiesel has gained much attention by the fact it has been regarded to be more environmental friendly and less carbon and particulate matter emitter during its combustion. ${ }^{16,26-32}$ But, if by one hand biodiesel is pointed to emit less regulated pollutants, such as $\mathrm{SO}_{2}, \mathrm{PM}, \mathrm{CO}$, among others (except for $\mathrm{NO}_{\mathrm{x}}$ ), on the other hand, when non-regulated species are considered there is an opposite trend. For instance, when some unregulated pollutants are studied, such as $\mathrm{O}_{3}$, carbonyl compounds, polycyclic aromatic compounds (PAH), and size classified particulate matter, it was found biodiesel generally emit higher levels of them than mineral diesel. ${ }^{8,32-36}$ Indeed, Guarieiro et al. ${ }^{8}$ has also reported that the more biodiesel is added to fossil diesel, the higher levels of reactive oxygen species (ROS) are produced into particles then demonstrating biodiesel particles exhaustion would be more toxic, at least in relation to ROS, than mineral diesel. This would be likely to rise more human health-related problems. To date, investigations about physical characterizations (such as particle size, particle morphology, and fractallike dimension) of nanoparticles and/or ultrafine particles emitted during biodiesel combustion, in comparison to fossil diesel burning emission, are rather insufficient to be completely understood.

In this study, we report results about fractal dimension and morphology of nanoparticles emitted by a diesel engine run with B4 (4\% biodiesel added to fossil diesel), B50 (50\% biodiesel added to fossil diesel), and B100 (100\% waste cooking oil biodiesel) set on a stationary dynamometer/CVS system. Fractal dimension, primary particles diameters, gyration diameters and investigations about morphology of ultrafine particles were done following the Neer and Koylu ${ }^{22}$ approach. Together to that, EC/OC levels were also measured and results are critically discussed.

\section{Experimental}

Fuels, engine characteristics and sampling experiments

In this study, there were used three different fuel compositions: B4 (4\% of commercial soybean oil biodiesel added to fossil diesel), B50 (50\% of waste cooking oil biodiesel to fossil diesel), and B100 (100\% waste cooking oil biodiesel). B4 was used in this investigation due to the fact no gas station in Brazil supplies pure mineral diesel (B0) since the Biodiesel Program has started at 2005. The B4 fuel was supplied by BR Petrobras Company (Petrobras Distribuidora, Brazil) and the B100 fuel was produced by the Biodiesel Pilot Plant from Federal University of Bahia (UFBA) (Salvador, Bahia, Brazil). The blend B50 was produced by mixing appropriate amounts of B4 and B100 fuels.

Emission studies were done with a diesel engine (Agrale, model M85, $10 \mathrm{HP}$ ) coupled to a steady-state dynamometer for sample collection. Details on the sampling experiments can be found in the first part of this study, published on Guarieiro et al. ${ }^{8}$ Information about physico-chemical B4 and B100 characteristics, engine specifications, and dynamometer/CVS system setups are found on Supplementary Information at Tables S1 and S2, 
and Figure S1, respectively. Briefly, the collection of samples was done at $1 \mathrm{~m}$ (PM2.5 system) and $4 \mathrm{~m}$ (PM2.5 and NanoMOUDI systems) away from the exhaust pipe and into the dilution chamber (Figure S1). The emission measurement system was operated under the constant volume principle (CVS), using a dilution tunnel ( $6 \mathrm{~m}$ long $\times 120 \mathrm{~mm}$ inner diameter). Engine exhausts were diluted with filtered scrubbed ambient air (air 0) in order to mimic real atmospheric dilution, which is likely to occur in ambient environments. The air flow in the CVS was set up to be under a constant dilution air-to-exhaust gas flow ratio of 15:1 (at $30 \mathrm{~m}^{3} \mathrm{~min}^{-1}$ ), with air velocity inside the tunnel around $44 \mathrm{~m} \mathrm{~s}^{-1}$ and Reynolds number of 74,000 in order to assure laminar air flow conditions.

Samples for chemical composition (OC/EC) were collected using two PM2.5 cyclone systems (PM2.5 Sharp cut cyclone, model VSCC-A, BGI Inc., USA), at point A and D ( 1 and $4 \mathrm{~m}$ away engine, respectively, Figure S1) in the dynamometer/CVS system. PM samples for OC/EC were collected at a flow rate of $10 \mathrm{~L} \mathrm{~min}^{-1}$, onto quartz filters ( $47 \mathrm{~mm}, 1 \mu \mathrm{m}$ pore size, Sartorius, Germany) during 1 hour per fuel. Prior to sample collection, quartz filters were pre-baked at $550{ }^{\circ} \mathrm{C}$ for $8 \mathrm{~h}$ then were stored in baked aluminum foil-lined containers. After sample collection, filters were kept in teflon-taped polypropylene Petri dishes (Waters, USA), and in the freezer under $4{ }^{\circ} \mathrm{C}$ until analysis. OC/EC measurements were done within 30 days after sampling.

Transmission electron microscope (TEM) samples were deposited on $3 \mathrm{~mm}$ TEM copper grid (Carbon Type-B, 300 mesh, Copper - Ted Pella, Inc., USA) attached to PTFE filter substrates placed in the $8^{\text {th }}$ to $14^{\text {th }}$ stages from the NanoMOUDI (14 stages, model 125B MSP Co., USA). The NanoMOUDI impactor worked at a flow rate of $30 \mathrm{~L} \mathrm{~min}^{-1}$, at point D (4 m away engine, Figure S1 only). The NanoMOUDI stages have the following nominal equivalent particle size cutoff diameter: 180-320 nm (stage \#8, S8), 100-180 nm (S9), 56-100 nm (S10), 32-56 nm (S11), 18-32 nm (S12), 10-18 (S13), and $\mathrm{d}_{\mathrm{p}}<10 \mathrm{~nm}$ (S14). Prior to any sample collection the engine was ran for $20 \mathrm{~min}$ with the test fuel in order to avoid possible cross-sample contaminations. In order to avoid particle saturation (and avoid particle possible build ups and overlaps) on top of TEM grid, it was submitted to particle laden flow for a very short period of time (up to $5 \mathrm{~min}$ ). Samples were collected in duplicate. Three blank tests were performed to assess data quality and analytical control. After each collection, grids were carefully removed from the probe by using tweezers and stored in a special protective box until TEM analyzes. TEM grid inspections started within 30 days after particle collection.

\section{Analysis of $\mathrm{OC}$ and EC contents}

EC/OC concentrations were measured by thermal optical transmittance (following the method proposed by Birch and Cary). ${ }^{37}$ Briefly, a $1.54 \mathrm{~cm}^{2}$ squared portion punch was taken from the sampled filters for analysis in the OCEC Analyzer (Sunset Laboratories, USA). During analysis, organic carbon content was volatilized from the sample in a pure helium atmosphere as the temperature has being stepped up to $820^{\circ} \mathrm{C}$. The evolved carbon was then catalytically oxidized to $\mathrm{CO}$, in a bed of granular $\mathrm{MnO}$, (held at about $900{ }^{\circ} \mathrm{C}$ ), then reduced to $\mathrm{CH}_{4}$ in a Ni/firebrick methanator (at $450{ }^{\circ} \mathrm{C}$ ), and quantified as $\mathrm{CH}_{4}$, by a flame ionization detector (FID). During the second analysis step, pyrolysis correction and EC measurement were made. The oven temperature was reduced, oxygen (10\%)-helium mix was introduced, and the oven temperature was then raised to about $860^{\circ} \mathrm{C}$. As oxygen entered the oven, EC pyrolyticallygenerated was oxidized and a concurrent increase in filter transmittance occurred. The carbon evolved in the first step was considered "organic" and carbon volatilized in the second step was considered "elemental".

\section{TEM image processing}

Grid image inspections were done by using a transmission electron microscope. A JEM-1200EX Transmission Electron Microscope JEOL with resolution of $0.2 \mathrm{~nm}$, and an accelerating voltage of $80 \mathrm{kV}$ was used in this work. The magnifications considered during the TEM inspections were in the range of $6,000 \times$ to 200,000×. Magnifications above 150,000× were used for measurements of spherule sizing while lower magnifications, in the range $6,000 \times$ to $30,000 \times$, were used for measuring aggregate sizes and morphologies. Micrographs were randomly taken at various locations across each grid surface due to the visual soot concentration to grid position in the exhaust stream.

Statistical data from the TEM images were done in order to obtain the distributions of primary particles and aggregates sizes as well as the fractal dimensions for particles emitted during the burning of B4, B50, and B100 fuels. Measurements were usually repeatable within the stated experimental uncertainties, which were dominated by the consideration of a finite number of particulates, primary particle overlap, dependence of thermophoresis on size and morphology, and image analysis biases. Another important image analysis weak point, which is inherent to this method, is implied by taking $2 \mathrm{D}$ images of 3D structures. Whenever 2D image representations of 3D materials are considered, there is an intrinsic reduction 
in the structural information which could reflect in deviations of both actual particle shape and in the fractallike dimension $\left(D_{\mathrm{f}}\right)$ results. Nevertheless, this approach is well-accepted and has been used by a number of studies, ${ }^{9,22,38-41}$ which demonstrates the image processing method applicability and reliability. Error propagations from the measurements to the calculated parameters were estimated within the $95 \%$ confidence level.

Particle size and fractal dimension analyses were performed using particle morphologies presented on TEM images. Image analyses (general aspect morphology of aggregates, measurement of primary particle diameter $\left(D_{p p}\right)$, projected aggregate areas $\left(A_{a}\right)$, characteristic aggregate lengths $(L)$, and aggregates gyration diameters $\left(D_{g}\right)$ ) were done using the Image $J$, which is an open source java image processing program software usually applied to processing and statistical analysis. Primary particles diameters $\left(\mathrm{D}_{\mathrm{pp}}\right)$ were found by measuring 60 primary particles at each TEM image from each fuel studied (B4, B50 and B100). In turn, aggregate gyration diameters $\left(\mathrm{D}_{\mathrm{g}}\right)$ were also measured at each TEM image sample. For $\mathrm{D}_{\mathrm{g}}$ measurements, it was measured from 150 to 750 aggregates in each grid. Uncertainties in $\mathrm{D}_{\mathrm{pp}}$ and $\mathrm{D}_{\mathrm{g}}$ were mostly due to some ambiguities with identifying spherule borders in the images and the conversion from pixel to nanometer scales.

According to Neer and Koylu, ${ }^{22} \mathrm{~N}_{\mathrm{pp}}, \mathrm{D}_{\mathrm{pp}}, \mathrm{D}_{\mathrm{g}}, \mathrm{A}_{\mathrm{a}}$ are directly related to fractal dimension $\left(\mathrm{D}_{\mathrm{f}}\right)$ as stated by equations 1 and 2, below:

$\mathrm{N}_{\mathrm{pp}}=\mathrm{k}_{\mathrm{a}}\left(\frac{\mathrm{A}_{\mathrm{a}}}{\mathrm{A}_{\mathrm{p}}}\right)^{\alpha}$

where $A_{a}$ is the aggregate projected area, $A_{p}$ is the average primary particle area $\left(\pi \mathrm{d}_{\mathrm{p}}^{-2} / 4\right)$, and $\mathrm{k}_{\mathrm{a}}=1.15$ and $\alpha=1.09$ are mathematical approachs for considering the likely of primary particles to have point overlap in the aggregates. ${ }^{22}$ Indeed, those $\mathrm{k}_{\mathrm{a}}$ and $\alpha$ values are also consistent with the findings from Brasil et al. ${ }^{38}$ and Wozniak et al. ${ }^{39}$ Yet, the primary particle number, $\mathrm{N}_{\mathrm{pp}}$, and its characteristic length (L) or aggregate gyration diameter $\left(\mathrm{D}_{\mathrm{g}}\right)$ are related as follow:

$N_{p p}=k_{L}\left(\frac{L}{D_{p p}}\right)^{D_{f}}=k_{f}\left(\frac{D_{g}}{D_{p p}}\right)^{D_{f}}$

where $D_{f}$ is the fractal dimension, $k_{L}$ is a correlation constant, and $\mathrm{k}_{\mathrm{f}}$ is the fractal prefactor (or a structural coefficient for possible void positions in the aggregate structure). ${ }^{22,38-41}$ The fractal-like dimension and the gyration diameter are considered to be as key parameters to describe aggregate morphology as well as soot properties. ${ }^{39}$
In this study, projected areas $\left(\mathrm{A}_{\mathrm{a}}\right)$ and maximum lengths (L) of 75 to 125 aggregates were directly measured from low-magnification $(6,000 \times$ to $30,000 \times)$ TEM images for each engine condition. $\mathrm{N}_{\mathrm{pp}}$ has correlated well with $\mathrm{L}$ when considering more than one thousand spherules, for all engine conditions and fuels tested. In this way, the power slope of the least square fit of the $\log -\log$ plot $\mathrm{N}_{\mathrm{pp}} v s$. $\mathrm{D}_{\mathrm{g}} / \mathrm{D}_{\mathrm{pp}}$ gave the fractal-like dimension $\left(D_{f}\right)$ of each fuel studied. In which the closer the $D_{f}$ value is to 1.0 the more chainlike the aggregate structure is. On the other hand, the more $D_{\mathrm{f}}$ tends to 3.0 the rounder and the more compact is the aggregate. $^{22,42}$

\section{Results and Discussion}

In regard to fuel composition, it is noteworthy to mention their related differences and/or similarities for each case. Firstly, fossil diesel is mainly composed by aliphatic saturated hydrocarbons ( $n$-alkanes) with carbon number ranging from $n-\mathrm{C}_{6}$ up to $n-\mathrm{C}_{20}$. The dominant portion of $n$-alkanes in the fossil diesel is mainly composed by $n$-tetradecane $\left(n-\mathrm{C}_{14}\right), n$-pentadecane $\left(n-\mathrm{C}_{15}\right)$, and $n$-hexadecane $\left(n-\mathrm{C}_{16}\right)$. Other straight-chain alkanes gradually decline from the main compounds $\left(n-\mathrm{C}_{14}\right.$ to $n-\mathrm{C}_{16}$ ) to either higher or lower carbon numbers, but they are minor constituents of petrodiesel. Branched alkanes and aromatics are presented in even lesser amount. ${ }^{33,43,44}$ On the other hand, pure soybean biodiesel presents as main components the methyl esters from the following acids: linoleic acid, oleic acid, and palmitic acid, as well as linolenic acid and stearic acid, in lesser amount. Taking into consideration waste cooking oil (WCO) in Brazil is mainly soybean oil which was used in successive thermal oxidative processes prior to its discharging, it is reasonable to assume WCO biodiesel is also mainly composed of the same major methyl esters but with a bigger contribution of minor short-chain organic components originated from the breakdown of the unsaturated fatty acids produced via temperature rising during cooking processes. ${ }^{8,33,43-45}$ Summing up, a priori, the employment of two biodiesels in this study did not interfere significantly in our results since we used chemically similar biodiesels (please also see Guarieiro et al. ${ }^{8,33,34}$ and references therein). In addition, possible changes in morphology and/or in the fractal dimension of particles emitted by burning of different fuels is negligible or has not been observed whatsoever. ${ }^{6,16,18}$ In this way, we may assume fractal dimension $\left(D_{f}\right)$ and other particle structure parameters, such as $D_{g}, D_{p p}$, and $N_{p p}$, would not be effectively affected by employing two different types of biodiesels or diesel/ biodiesel mixes. 


\section{OC/EC emission factors}

Organic carbon (OC) and elemental carbon (EC) samples were collected in both point A (1 m away from exhaust mix) and point D (4 m away from exhaust mix) on the dynamometer/CVS system as observed in Figure S1. OC and EC factor emissions were calculated as micrograms $(\mu \mathrm{g})$ of either OC or EC emitted per kilogram of burned fuel mix ( $\left.\mu \mathrm{g} \mathrm{kg}_{\text {fuel }}{ }^{-1}\right)$. Organic carbon factor emissions (units in $\mu \mathrm{kg}_{\text {fuel }}{ }^{-1}$ ) ranged from 842 (point $\mathrm{A}$ ) to 1243 (point D), 466 (point A) to 895 (point D), and 508 (point A) to 892 (point D) for B4, B50, and B100, respectively. In the same way, $\mathrm{EC}$ factor emissions (units in $\mu \mathrm{g} \mathrm{kg}_{\text {fuel }}{ }^{-1}$ ) were 399 (point A) to 692 (point D), 219 (point A) to 413 (point D), and 667 (point A) to 1144 (point D), B4, B50, and B100, respectively.

In considering the values of $\mathrm{OC}$ and $\mathrm{EC}$ emission factors individually as well as the ratio OC/EC emission factors (Figure 1a), OC emission factors were about 2 times higher than EC emission factors, for every studied fuel or fuel mix. Additionally, results from Figure $1 \mathrm{~b}$ show a similar emission profile for points $\mathrm{A}$ and $\mathrm{D}$ but the point $\mathrm{D}$ OC and EC percentages in total carbon were 2-3 times higher than those ones from point A, for either B4, B50, or B100. Higher levels in point $\mathrm{D}$ than in point $\mathrm{A}$ are related to the exhaustion cooling as it goes through the CVS and gradually moves away from the engine. This makes particle size growing by successive condensation, nucleation and/or agglomeration processes and more efficient gas-to-particle conversions. When comparing OC emission factors among the tested fuels, this is observed an increase in $\mathrm{OC}$ emission when more biodiesel is added to fossil diesel. On the other hand, EC emission factor decreases when more biodiesel is added. The increase trend of $\mathrm{OC}$ and the decrease trend of EC emission factors may influence directly the aggregate particle physical properties since they act as supporting substrates for condensation of weakly volatile gaseous and/or liquid species on aggregated particles surfaces. This could probably contribute to make changes in the structure, size, morphology, and therefore, in the fractal dimension of aggregated particles emitted by the burning of diesel/ biodiesel blends.

Another useful point of view is to consider the combustion process by itself for explaining the OC/EC emission trend observed in this study. Taking in consideration combustion is an inherent oxidative process, which, in the hypothetically rigorously efficient conditions should convert all organic matter content into carbon dioxide and water. In this way, under these conditions, $n$-alkanes (as those presented by fossil diesel) would be gradually oxidized and be converted to alcohols, then to carbonyl compounds, then to carboxylic acids, then to esters and finally yielding to carbon dioxide. However, it is known and well-accepted that no real engine system possesses such efficiency and, therefore, total conversion of organic matter to carbon dioxide and water does not happen in real world conditions. There would have an array of conditions (such as oxygen-to-fuel ratio, combustion temperature, energy, compression rate, among others) during fuel burning in the combustion chamber that results in a lower combustion efficiency.
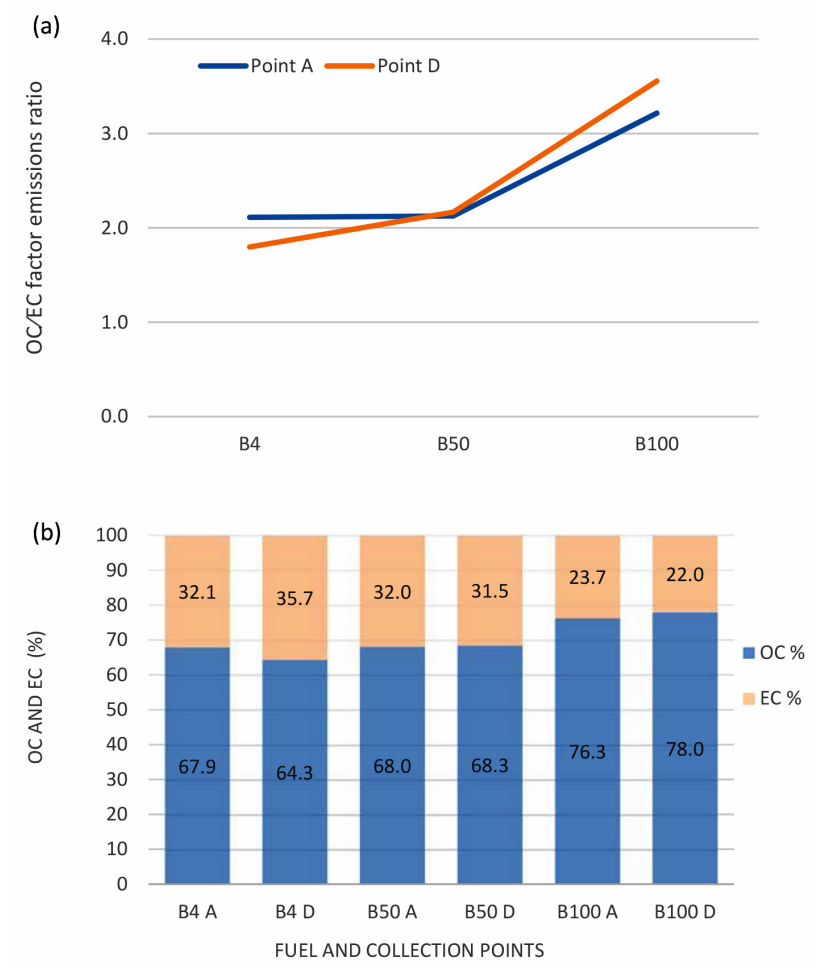

Figure 1. (a) OC and EC emission factors as micrograms $(\mu \mathrm{g})$ of $\mathrm{OC}$ or EC emitted per kilograms $(\mathrm{kg})$ of burnt fuel $\left(\mu \mathrm{gg}_{\text {fuel }}{ }^{-1}\right)$ for B4, B50 and B100; and (b) OC and EC percentages in total carbon, in points A and $\mathrm{D}$, for the studied fuel blends.

In this way, in real and incomplete combustion conditions, it also is formed elemental carbon (EC, the less oxidized combustion product) and a number of different organic products (from $n$-alkanes to alcohols, carbonyls, carboxyls, and esters), which are represented here as organic carbon or OC, and/or finally carbon dioxide, which is the most oxidized product. ${ }^{8,33,44}$ On the other hand, when burning biodiesel, which is mainly fatty acid methyl esters, it is a reasonable assumption that under real diesel engine combustion conditions it would be more prone to convert esters to carbon dioxide, which is less energy-demanding. In this way, when burning biodiesel, it would be emitted a proportionally lower quantity of EC and a higher ratio of $\mathrm{OC}$ in relation to EC, as observed by Figures $1 \mathrm{a}$ and $1 \mathrm{~b}$. 
Our findings are consistent with this mechanistic discussion about fuel combustion.

Another portion of OC levels observed in the present study is likely to be derived from the unburned petrodiesel and/or biodiesel. Due to the same inherent inefficiency of any diesel engine, during fuel combustion a portion of the fuel admitted in the combustion chamber does not meet the characteristic parameters needed to be actually burned. In this way, some fuel remains unburned and then it is expelled off the engine nearly chemically unmodified. Due to the high temperature and pressure this unburned fuel portion was undertaken in the combustion chamber, it is likely to be released within the exhaust as low-volatile vapor or as part of OC content of particulate matter (PM). Yet, during the exhaust cooling process in the CVS, this portion of unburned fuel primarily emitted as low-volatile vapor probably is transferred onto pre-existing PM, possibly being either absorbed or adsorbed or both. This would contribute for the particle size growth, increasing primary particle diameter $\left(\mathrm{D}_{\mathrm{pp}}\right)$ or generating and adding up new primary particles (increasing $\mathrm{N}_{\mathrm{pp}}$ ) to agglomerates and then increasing particle size (or increasing agglomerate gyration diameter, $\mathrm{D}_{\mathrm{g}}$ ). Depending on how much this process happens it would be virtually possible to modify the fractal dimension $\left(D_{f}\right)$ in some extension.

\section{TEM observations}

Typical particles TEM images are shown in Figures 2 and 3 . In these figures, there are particles emitted by a diesel engine fueled with B4, B50, and B100, at low conditions (low load). TEM samples were collected in the stages S8 (180-320 nm), S9 (100-180 nm), S10 (56-100 nm), $\mathrm{S} 11$ (32-56 nm), S12 (18-32 nm), S13 (10-18 nm), and $\mathrm{S} 14(<10 \mathrm{~nm})$ of a NanoMOUDI sampler.

In general, TEM images have demonstrated essential features of diesel soot emission, with apparent fractal geometry, which are similar to those reported elsewhere. ${ }^{6,16,22}$ However, it was not possible to distinguish different particle formats among the tested fuels (B4, B50, and B100). For all fuels, particles presented slightly different shapes with grapelike structures and cluster-cluster type formations, as indicated by red circles in Figure 2. Some of those small particle aggregates are composed of some tens to few hundreds of primary particles. These small new particles could have been nucleated in the combustion chamber and freshly emitted by the engine.

Indeed, those such small particles or particle aggregates are of major environmental and human health concerns. In the environmental point of view, those very small particles are likely to possess large superficial area, which become a very active surface for both chemical (diverse reactions) and physical (condensation/evaporation, coagulation, gas-to-particle conversions) processes to occur, or absorption and adsorption processes, respectively. These multiple processes can potentially modify particles' compositions and influence air quality of a given region. In turn, regarding human health, ultrafine freshly emitted particles as seems to have happened during tests done using B4, B50, and B100, are able to go more profoundly
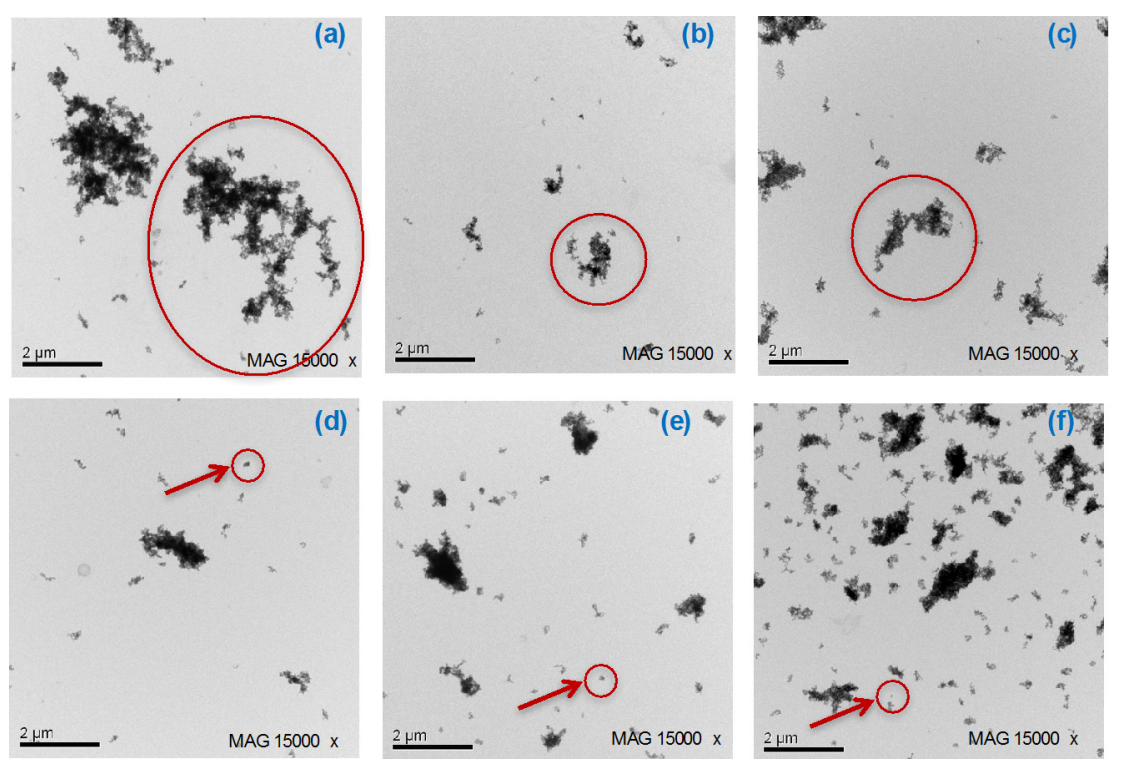

Figure 2. Low magnification (15000x) TEM images of particulates of diesel exhaust run with diesel with $4 \%$ of soy biodiesel (B4), diesel/biodiesel 50\% blend (B50) and 100\% waste cooking oil biodiesel (B100) collected in the S8, S9 and S10 stages of the NanoMOUDI sampler. In (a), (b), and (c) it is highlighted by the red circles cluster-cluster formations while in (d), (e), and (f) red arrows and circles show grapelike structures. 

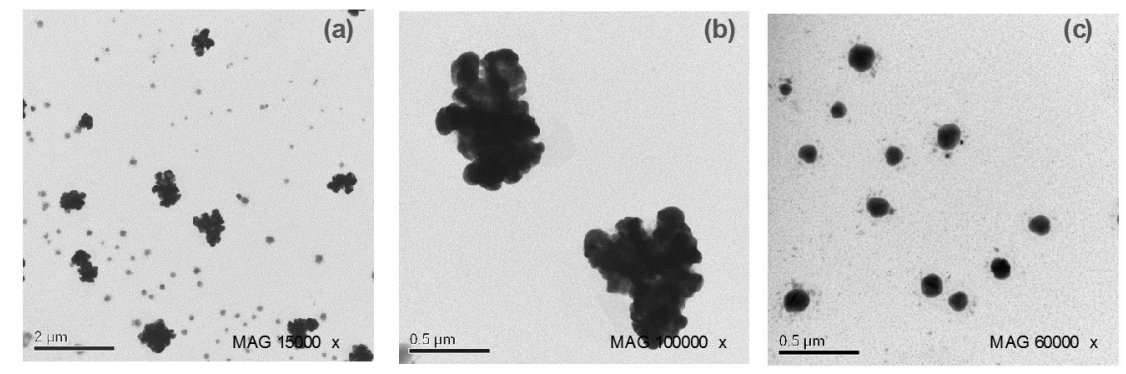

Figure 3. TEM images of particulates exhausted from 100\% waste cooking oil biodiesel (B100) combustions, collected in the latter stages, (a) stage S11, (b) stage S12, and (c) stage S13 of the NanoMOUDI impactor.

in the human respiratory system, which may trigger a series of health endpoints.

High magnification TEM micrographs (Figures 2 and 3) were taken in order to identify more detailed structures from different fuels (and also from the latter stages of NanoMOUDI). In Figure 3c, it is noted a different type of structure for particle aggregates in B100 (collected in the $\mathrm{S} 13$ but also stages S11, S12, and S14), which does not follow a fractal geometry anymore. The same occurs for particles from S13 and S14 for both B50 and B100 (as exemplified by Figures $3 b$ and $3 c$ ). In these occurrences, it is not possible to observe any primary particles anymore. They are rather better classified as amorphous and irregular particles, with diffuse borders. When comparing them to particles found in B4 (which have shown themselves as primary particles aggregates as grapelike formations in all stages for all fuels), it could be interpreted that the increase in the biodiesel addition to fossil diesel is likely to have contributed to modify the particle formats from B50 and $\mathrm{B} 100$, and may be the reason particle aggregates does not follow a fractal structure anymore in these cases. The morphological profile on irregular amorphous particles with mainly diffuse edges emitted from B100 burning was found S10-S14 stages. According to Barone and Zhu, ${ }^{24}$ this kind of particle formations are solids composed by low volatility liquids, which are formed depending on the potency and engine operation conditions. In the Figures $3 b$ and $3 \mathrm{c}$ particles look like as if they were several liquid-like particles without defined spherules nor fractal geometry structures. Since our samples were collected at low load conditions, we observe particle images with particles' appearance of a nebulous and amorphous structures. Our findings are also consistent with some studies with collected particles within similar conditions, also using biodiesel as fuel. ${ }^{46}$

Considering that OC levels are increased in B100 in relation to $\mathrm{B} 4$ as well as the $\mathrm{PAH}$ emission factors are higher in B100 (in comparison to B4), as demonstrated in the first part of our study (found on Guarieiro et al.), ${ }^{8}$ these findings are related to each other. These irregularities in the particle shapes could be due to higher levels of low volatility viscous organic compounds emitted during B100 burning, derived either from the incomplete burned fuel or from the low-volatile vapor unburned fuel fractions or both. In turn, if $\mathrm{OC}$ levels rise, the EC levels decreases when biodiesel (B100) is used. In this way, carbonaceous particles from EC is limited in B100 exhaust what could difficult to promote a more defined structure such as grapelike soot particles as in typical diesel soot formations. This would also favor the formation of liquid-like particles in the case more biodiesel (B50 and B100) is available in the fuel burned. Also, if the amount of organic species and the probable large variety of them would be the main substances composing smaller particles from B100 burning, this could be an indicative that such particles would be more toxic than particles emitted from fuel blends with lower biodiesel content (as found in DTT assay results at Guarieiro et al. .) ${ }^{8}$

\section{Particle size and fractal dimension measurements}

Quantifications of particle size by measuring primary particle diameter $\left(\mathrm{D}_{\mathrm{pp}}\right)$ and aggregate gyration diameter $\left(\mathrm{D}_{\mathrm{g}}\right)$ were made for each fuel, from S8-S11 NanoMOUDI stages. Results from S12 and S13 stages were not used in the present study since they did not present enough number of spherules for having been consistently measured. The apparent primary particles profiles were visually detected at high magnifications around the edges of multiple aggregates.

Figure 4a and Table 1 present statistical primary particle diameter measurements for each fuel in S8-S11 stages samples. The number-averaged $\mathrm{D}_{\mathrm{pp}}$ is $24 \pm 4 \mathrm{~nm}$ for B4, $23 \pm 4 \mathrm{~nm}$ for B50, and $20 \pm 4 \mathrm{~nm}$ for B100. A narrow $\mathrm{D}_{\mathrm{pp}}$ range (13-38 $\mathrm{nm}$ for $\mathrm{B} 4,13-40 \mathrm{~nm}$ for $\mathrm{B} 50$, and $10-38 \mathrm{~nm}$ for B100) together with small standard deviation values show the low variability of primary particle size.

This is indicative the particle aggregates are nearly monodispersed and they are representative of fractal structures, as expected to be from diesel soot particles. Although it is observed a weak trend of $\mathrm{D}_{\mathrm{pp}}$ reduction 
Table 1. Fractal-like parameters measurements $\left(\mathrm{D}_{\mathrm{pp}}\right.$ and $\left.\mathrm{D}_{\mathrm{g}}\right)$ or calculated $\left(\mathrm{N}_{\mathrm{pp}}\right)$

\begin{tabular}{lccc}
\hline Morphological parameters & $\mathrm{B} 4$ & $\mathrm{~B} 50$ & $\mathrm{~B} 100$ \\
\hline Primary particle diameter, $\mathrm{D}_{\mathrm{pp}} / \mathrm{nm}$ & & \\
Mean $\pm \mathrm{sd}^{\mathrm{a}}$ & $24 \pm 4$ & $23 \pm 4$ & $20 \pm 4$ \\
Range $^{\mathrm{b}}$ & $13-38$ & $13-40$ & $10-38$ \\
$\mathrm{RSD} / \%)$ & 18 & 17 & 22 \\
\hline Aggregate gyration diameter, $\mathrm{D}_{\mathrm{g}} / \mathrm{nm}$ & & \\
Mean \pm sd & $242 \pm 140$ & $210 \pm 135$ & $232 \pm 140$ \\
Range & $32-649$ & $31-626$ & $43-600$ \\
RSD / \% & 58 & 65 & 59 \\
\hline Primary particle number, $\mathrm{N}_{\mathrm{pp}}{ }^{\mathrm{d}}$ & & & \\
Mean \pm sd & $159 \pm 163$ & $156 \pm 149$ & $150 \pm 168$ \\
Range & $10-713$ & $10-683$ & $10-743$ \\
RSD / \% & 103 & 95 & 112 \\
\hline Fractal-like dimension, $\mathrm{D}_{\mathrm{f}}^{\mathrm{d}, \mathrm{e}}$ & & & \\
log-log plot $\mathrm{N}_{\mathrm{pp}} v s . \mathrm{D}_{\mathrm{g}} / \mathrm{D}_{\mathrm{pp}}$ & 1.9413 & 1.8852 & 1.9878 \\
\hline
\end{tabular}

a Arithmetic mean \pm one standard deviation; binterval between the minimum and maximum found values; crelative standard deviation in terms of percentage; ${ }^{\mathrm{d}} \mathrm{N}_{\mathrm{pp}}$ and $\mathrm{D}_{\mathrm{f}}$ are dimensionless parameters; ${ }^{\mathrm{e}}$ see Figure 5.

when increasing the relative amount of biodiesel added to petrodiesel, this is not enough to consider those small differences in the primary particle diameter statistically significant. In this way, we consider the average $\mathrm{D}_{\mathrm{pp}}$ weak variability among different fuels or fuel mixes is within the random experimental error. Therefore, agglomerate particles were constituted by spherules with nearly the same size, regardless the fuel composition.

In turn, aggregate gyration diameters $\left(\mathrm{D}_{\mathrm{g}}\right)$ ranged from $242 \pm 140 \mathrm{~nm}, 210 \pm 135 \mathrm{~nm}$, and to $232 \pm 140 \mathrm{~nm}$ for B4, B50, and B100, respectively (Table 1 and Figure 4b). An average primary particle number $\left(\mathrm{N}_{\mathrm{pp}}\right)$ of $159 \pm 163$, $156 \pm 149$, and $150 \pm 168$ were found for B4, B50, and B100, respectively (Table 1). As we can see, for both $D_{g}$ and $\mathrm{N}_{\mathrm{pp}}$ there are a large variation of those values around the mean values, indicating a found relatively wide $\mathrm{D}_{\mathrm{g}}$ range (32-649 $\mathrm{nm}$ (B4), 31-626 nm (B50), and 43-600 nm (B100)) as well as wide $\mathrm{N}_{\mathrm{pp}}$ range (10-713 spherules (B4), 10-683 spherules (B50), and 10-743 spherules (B100)) thus indicating fuel combustion in the diesel engine yielded agglomerate particles constituted ranging from few monomers to larger and probably more structured agglomerates arranged within a fractal geometry. Considering our sampling setup, when particles and/or low-volatile vapor were freshly exhausted out the engine under laminar flow, they were allowed to be cooled down and then reorganize in fractal soot structures within a $4 \mathrm{~m}$ long dilution tunnel from CVS system. This particle sizing range found here is a result of many physical and chemical successive processes (such as nucleation, gas-to-particle conversion, agglomeration, condensation, among others) exhaust underwent in order to organize itself into fractal soot agglomerates within such size ranges.

Primary particle number $\left(\mathrm{N}_{\mathrm{pp}}\right)$ correlated well with $\mathrm{D}_{\mathrm{g}}$ for B4, B50, and B100 fuels, presenting a few more than one thousand spherules. Fractal dimensions $\left(D_{\mathrm{f}}\right)$ were calculated by the logarithmical relation of $\mathrm{N}_{\mathrm{pp}}$ versus $\mathrm{D}_{\mathrm{g}} / \mathrm{D}_{\mathrm{pp}}$ for $\mathrm{B} 4$ (Figure 5a), B50 (Figure 5b), and B100 (Figure 5c). Both calculated $\mathrm{D}_{\mathrm{f}}$ were $1.94,1.89$, and 1.99 and $\mathrm{k}_{\mathrm{L}}$ were 1.00 , 1.12 , and 0.91 for B4, B50, and B100, respectively. When trying to compare $\mathrm{N}_{\mathrm{pp}}, \mathrm{D}_{\mathrm{g}}, \mathrm{k}_{\mathrm{L}}$, and $\mathrm{D}_{\mathrm{f}}$, we do not see any trend according to fuel composition. So, in regard to those morphological parameters, burning of B4, B50, and/or B100 yielded soot with similar fractal structure for those agglomerates from stages S8-S11 from the NanoMOUDI.

Besides the parameters $\mathrm{N}_{\mathrm{pp}}, \mathrm{D}_{\mathrm{pp}}, \mathrm{D}_{\mathrm{g}}$ and $\mathrm{D}_{\mathrm{f}}$ already presented here, another important parameter is the fractal prefactor, $\mathrm{k}_{\mathrm{f}}$, in order to fully characterize the morphology and size of particle agglomerates. Small $\mathrm{k}_{\mathrm{f}}$ values implies more elongated and larger overall dimensions even for a pool of aggregates with the same $\mathrm{N}_{\mathrm{pp}}$ and $\mathrm{D}_{\mathrm{f}}$ values. ${ }^{22}$ One such limitation is related to not being possible to measure $\mathrm{k}_{\mathrm{f}}$ directly in studies about diesel engines. However, according to Neer and Koylu ${ }^{22} \mathrm{k}_{\mathrm{f}}$ can be calculated by the following relationship:

$\frac{k_{f}}{k_{L}}=\left(\frac{D_{f}+2}{D_{f}}\right)^{D_{f} / 2}$

In this way, in our calculations we found $\mathrm{k}_{\mathrm{f}}$ to be equal to $1.99,2.22$, and 1.82 for B4, B50, and B100, respectively. We tentatively interpret these values as indicative primary particles are nearly round, regardless the fuel composition. Neer and Koylu ${ }^{22}$ (and references therein) found fractal prefactor values in the range 1.3-2.4 for internal combustion engines. The found $\mathrm{k}_{\mathrm{f}}$ values in this study are consistent with those accepted values.

According to fractal models stated by Schaefer ${ }^{42}$ we may consider particle formation, aggregation, transport and growth was done under diffusion-limited cluster aggregation (DLCA). According to Schaefer ${ }^{42}$ when exhausts exit the combustion chamber very small particle nuclei (or spherules and/or single primary particles) are randomly moving into the CVS dilution tunnel as they cool down. Eventually few single primary particles meet each other forming a chain-like, and then grapelike structure and the fractal self-organization is started. As these grapelike primary particle agglomerates continue to move away from the engine, a union of some of them is formed and then a 

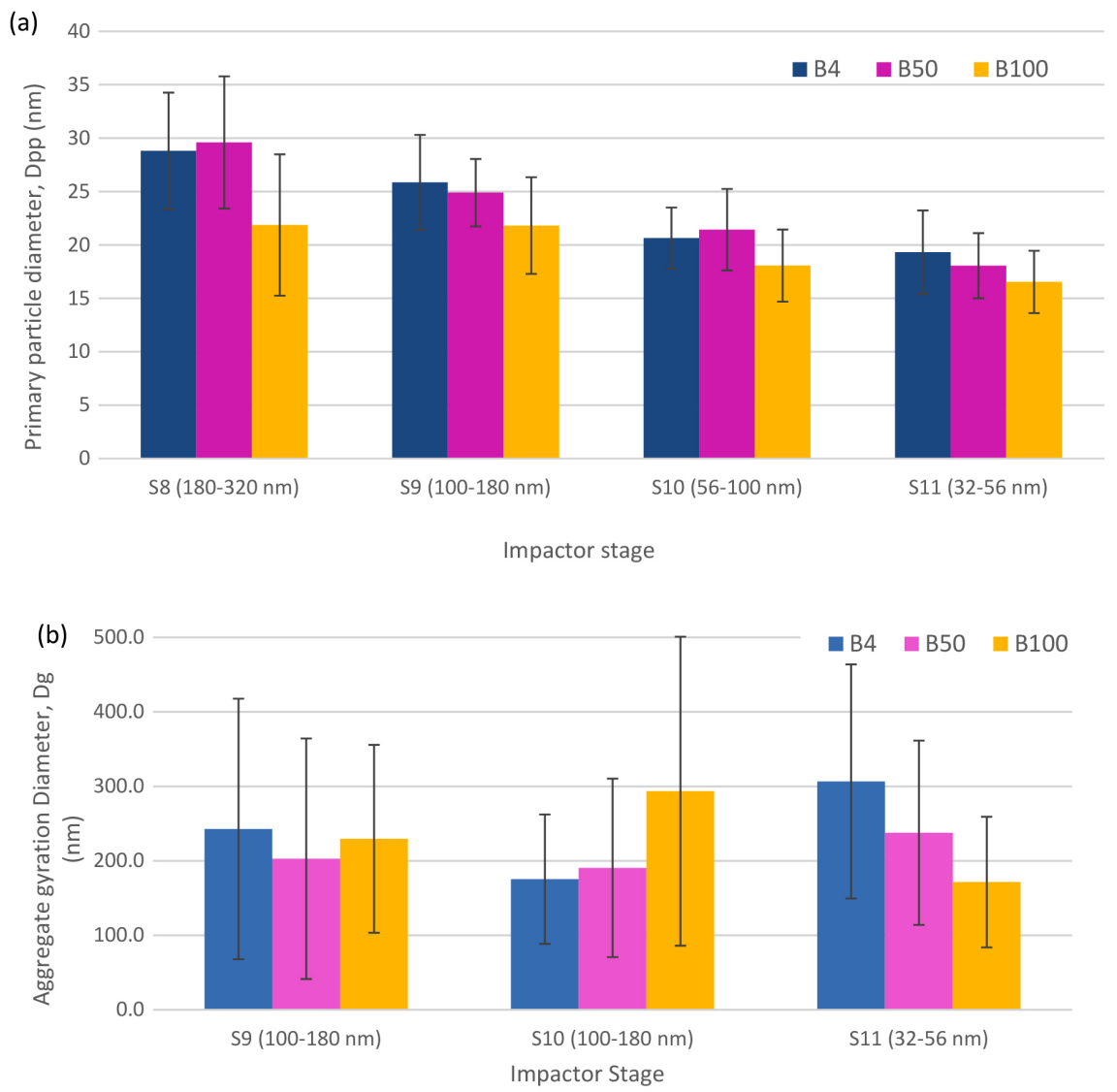

Figure 4. (a) Primary particle diameter and (b) aggregate gyration diameter measurements for B4, B50, and B100 fuels on S8 (180-320 nm), S9 (100-180 nm), S10 (56-100 nm), and S11 (32-56 nm) NanoMOUDI collection stages.

cluster is formed and it moves as a unit. The result of this process is an open fractal structure with avoid positions with no obvious center, as we see in Figures 2 and 3. Indeed, the DLCA condition, generally soot agglomerates are arranged in a fractal geometry though they present hollow, less dense structures. If particle agglomerates are relatively hollow they are likely to stay suspended in the air for a longer time than a more compact agglomerate. When particle agglomerate soot is formed under DLCA regime, the theoretical accepted value of $\mathrm{D}_{\mathrm{f}}$ is around 1.80. In Table 2, we compare our results with other reported studies, which used either diesel, biodiesel or natural gas in their studies. In these studies, $\mathrm{D}_{\mathrm{f}}$ ranged from 1.50 to 2.18. Taking into consideration these studies have used different experimental setups, different combustion regimes, and different engine technologies, we consider our results are in good agreement with them. In the same way, we also say our results for $D_{g}$ and $\mathrm{D}_{\mathrm{pp}}$ are consistent with the literature (Table 2).

Adopting the fractal geometry concept to describe carbonaceous diesel soot may rise practical implications in different areas. First of all, for practical purposes, in many aspects of Atmospheric Sciences we assume an atmospheric particle as a sphere with density of $1 \mathrm{~g} \mathrm{~cm}^{-3}$. And with this assumption, we derive and/or define particle surface, particle volume, particle number concentration, and particle mass concentration only to name a few parameters to be applied to most of practical applications and the development of particle measurement instrumentation. Accordingly, atmospheric particle reactivity towards formation of secondary organic aerosols (SOA) and models for particle transportation and particle respiratory tract deposition also are based in the same approximation. So, this may lead to a divergent understanding of actually happens in the nature or in biological systems. In this way, it would be useful to consider the real fractal geometry of carbonaceous soot (or the amorphous and diffuse structure found in B50 and B100) in order to develop a better and more realistic comprehension of atmospheric and biological processes carbonaceous particles may undergo. Meanwhile, it is likely fractal (or amorphous) soot properties are well different from the hypothetical spherical particle model, and this can affect significantly their deposition and how they interact with lung epithelial cells (or even other types of cells in human body). However, to date it still is not completely understood the causal relation among particle, size, structure, morphology, toxicology and the development 

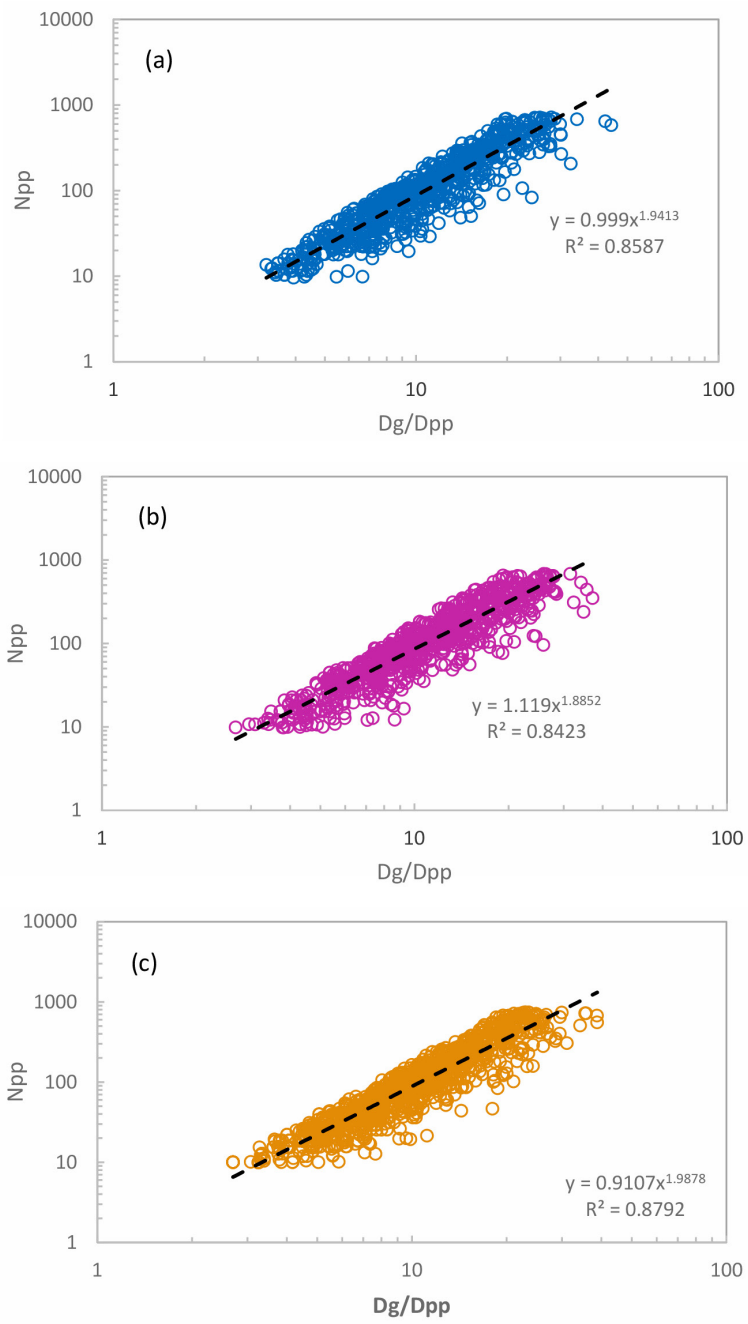

Figure 5. Statistical determinations of average fractal properties for particles emitted during (a) B4, (b) B50, and (c) B100 combustions. of health-related symptoms. By not considering the exact particle geometry it may be contributing to inaccurate understandings and accepted models. Finally, in terms of engine technology, the consideration of the fractal geometry of soot particles may help to develop more efficient engines by improving the combustion step as well as automobile catalyst systems able to emit ultrafine particle in lower levels, minimizing air pollution around large cities. If also considering the formation of amorphous particles when more biodiesel is added to fossil diesel it may contribute to the synthesis of new additives for oxygenate fuels in order to improve combustion characteristics and predict particle geometry.

\section{Conclusions}

This study investigated the fractal nature of diesel soot agglomerates emitted from combustion of diesel and biodiesel blends. Results from this study indicates that OC/EC content of $\mathrm{PM}_{2.5}$ samples was altered by the addition of biodiesel to petrodiesel as well as general aspect morphologies. When more biodiesel was added to petrodiesel, a larger contribution of non-fractal particles with diffuse edges were observed. TEM images showed liquid-like particles mostly present for B50 and B100 for particles collected after the $10^{\text {th }}$ stage of the NanoMOUDI impactor.

On the other hand, particle agglomerates collected from the $8^{\text {th }}$ to $11^{\text {th }}$ impactor stages showed fractal-like geometry. In these cases, average particle size was $242 \mathrm{~nm}$ (B4), $210 \mathrm{~nm}$ (B50), and $232 \mathrm{~nm}$ (B100), being composed by round spherules of $24 \mathrm{~nm}$ (B4), $23 \mathrm{~nm}$ (B50), and $20 \mathrm{~nm}$ (B100).

Table 2. Comparisons of fractal dimension and morphology of soot agglomerates among previously published studies and the present investigation

\begin{tabular}{|c|c|c|c|c|}
\hline Publication & Engine type $(\mathrm{B} / \mathrm{D})^{\mathrm{a}}$ & $\mathrm{D}_{\mathrm{f}}$ & $\mathrm{D}_{\mathrm{g}}^{\mathrm{b}} / \mathrm{nm}$ & $\mathrm{D}_{\mathrm{pp}}^{\mathrm{b}} / \mathrm{nm}$ \\
\hline This study & diesel engine, $6.0 \mathrm{~L}, 2$ cylinders, $(\mathrm{B} / \mathrm{D})$ & $\begin{array}{c}1.94 \text { (B4) } \\
1.89 \text { (B50) } \\
1.99 \text { (B100) }\end{array}$ & $\begin{array}{c}242 \pm 140 \text { (B4) } \\
210 \pm 135 \text { (B50) } \\
232 \pm 140 \text { (B100) }\end{array}$ & $\begin{array}{c}24 \pm 4(\mathrm{~B} 4) \\
23 \pm 4(\mathrm{~B} 50) \\
20 \pm 4(\mathrm{~B} 100)\end{array}$ \\
\hline Mustafi and Raine ${ }^{2}$ & diesel engine, (D/natural gas) & $\begin{array}{c}1.73-1.88(\mathrm{D} / \mathrm{NG}) \\
1.69(\mathrm{D})\end{array}$ & ND & $\begin{array}{c}26.9-29.5(\mathrm{D} / \mathrm{NG}) \\
26.4(\mathrm{D})\end{array}$ \\
\hline Savic et al. ${ }^{16}$ & diesel engine, Euro IV car, 4 cylinders, (B/D) & $\begin{array}{l}2.18 \pm 0.1(\mathrm{~B}) \\
1.71 \pm 0.1(\mathrm{D})\end{array}$ & $55-155$ & $\begin{array}{l}12-19(\mathrm{~B}) \\
19-23(\mathrm{D})\end{array}$ \\
\hline Neer and Koylu ${ }^{22}$ & diesel engine, $5.9 \mathrm{~L}$, (D) & $1.77 \pm 0.13$ & $160-350$ & $20-35$ \\
\hline Ajtai et $a l .{ }^{23}$ & diesel engine, 6 cylinders, (B/D) & ND & ND & $7-10$ \\
\hline Lapuerta et al. ${ }^{29}$ & diesel engine, 1.7 L, 4 cylinders, (D) & ND & ND & $23.51 \pm 6.41$ \\
\hline Traviss et al. ${ }^{31}$ & non-road diesel engine, (B20/D) & $\begin{array}{c}1.63(\mathrm{D}) \\
1.61(\mathrm{~B} 20)\end{array}$ & $\begin{array}{l}109 \pm 16.1(\mathrm{D}) \\
99 \pm 9.7(\mathrm{~B} 20)\end{array}$ & $\begin{array}{c}10.8 \pm 3.8(\mathrm{D}) \\
10.7 \pm 3.2(\mathrm{~B} 20)\end{array}$ \\
\hline Seong et al. ${ }^{47}$ & diesel engine, $0.48 \mathrm{~L}, 1$ cylinder (B/D) & $1.57-1.73$ & $22-31$ & $11-17$ \\
\hline Lu et al..$^{48}$ & diesel engine, 4 cylinders, (D) & ND & ND & $23.8-28.5$ \\
\hline Chandler et al. ${ }^{49}$ & non-road diesel engine, $5.9 \mathrm{~L},(\mathrm{D})$ & $1.70-1.90$ & $78-135$ & $20-30$ \\
\hline Lee et $a l . .^{50}$ & diesel engine, 1.7 L, 4 cylinders, (D) & $1.50-1.70$ & $77-134$ & $22 \pm 2$ \\
\hline Lee et $a l .^{51}$ & diesel engine, $1.7 \mathrm{~L}, 4$ cylinders, (D) & $1.46-1.73$ & $50-102$ & $32 \pm 3$ \\
\hline
\end{tabular}

${ }^{\mathrm{a}} \mathrm{B}=$ biodiesel fuel, and $\mathrm{D}=$ mineral diesel fuel; bin some studies it is reported $\mathrm{r}_{\mathrm{g}}$ and $\mathrm{r}_{\mathrm{pp}}$, meaning gyration radius and primary particle radius, respectively. Whenever it happened we considered $D_{g}=2 \times r_{g}$ and $D_{p p}=2 \times r_{p p}$ for the ease of comparing among results from different studies. ND = not determined; $\mathrm{NG}=$ natural gas. 
Fractal dimension of aggregates were 1.94 (B4), 1.89 (B50), and 1.99 (B100), which shows formation and growth under diffusion-limited cluster aggregation. Morphological parameter results show agglomerates were self-arranged in fractal geometry, with similar fractal dimension values, regardless the fuel composition.

\section{Supplementary Information}

Supplementary information is available free of charge at http://jbcs.sbq.org.br as a PDF file.

\section{Acknowledgments}

Authors are thankful for Prof Dr Leonardo S. G. Teixeira for analyses of both commercial diesel and biodiesel and Prof Dr Antonio H. Miguel for his helpful suggestions in this work. We acknowledge Prof Dr Ednildo A. Torres and Prof Dr João Victor S. Santos for helping in the particle sampling and Marina C. Rodrigues for helping in the image processing. Authors also thank for the following funding resources: PETROBRAS S/A, CNPq, CAPES, FAPESB, CNPq/FAPESB/PRONEX.

\section{References}

1. Wang, Y.; Liang, X.; Shu, G.; Dong, L.; Sun, X.; Yu, H.; Tribol. Int. 2015, 92, 379.

2. Mustafi, N. N.; Raine, R. R.; Aerosol Sci. Technol. 2009, 43, 951.

3. Broday, D. M.; Rosenzweig, R.; J. Aerosol Sci. 2011, 42, 372.

4. Shukla, P. C.; Gupta, T.; Agarwal, A. K.; Aerosol Air Qual. Res. 2014, 14, 934.

5. Chin-Hsiang, L.; Whey-May, L.; Jiun-Jian, L.; J. Environ. Sci. 2009, 21, 452 .

6. Choi, S.; Myung, C. L.; Park, S.; Int. J. Automot. Technol. 2014, $15,219$.

7. Myung, C. L.; Ko, A.; Park, S.; Int. J. Automot. Technol. 2014, $15,203$.

8. Guarieiro, A. L. N.; Santos, J. V. S.; Eiguren-Fernandez, A.; Torres, E. A.; da Rocha, G. O.; de Andrade, J. B.; Fuel 2014, 116, 490.

9. Kam, W.; Liacos, J.W.; Schauer, J. J.; Delfino, R. J.; Sioutas, C.; Atmos. Environ. 2012, 55, 90.

10. Pope, C. A.; Dockery, D.; J. Air Waste Manage. Assoc. 2006, 56, 709.

11. Pope, C. A.; Ezzati, M.; Dockery, D. W.; New Engl. J. Med. 2009, 360, 376.

12. Ayres, J. G.; Borm, P.; Cassee, F. R.; Castranova, V.; Donaldson, K.; Ghio, K.; Harrison, R. M.; Hider, R.; Kelly, F.; Kooter, I. M.; Inhal. Toxicol. 2008, 20, 75.
13. Tzamkiozis, T.; Ntziachristos, L.; Mamakos, A.; Fontaras, G.; Samaras, Z.; Aerosol Sci. Technol. 2011, 45, 587.

14. Klot, S. V.; Wölke, G.; Tuch, T.; Heinrich. J.; Dockery, D. W.; Schwartz, J.; Kreyling, W. G.; Wichman, H. E.; Peters, A.; Eur. Respir. J. 2002, 20, 69.

15. Fanning, E. W.; Froines, J. R.; Utell, M. J.; Lippmann, M.; Oberdörster, G.; Frampton, M.; Godleski, J.; Larson, T. V.; Environ. Health Persp. 2009, 117, 167.

16. Savic, N.; Rahman, M. M.; Miljevic, B.; Saathoff, H.; Naumann, K. H.; Leisner, T.; Riches, J.; Gupta, B.; Motta, N.; Ristovski, Z. D.; Carbon 2016, 104, 179.

17. Eggersdorfer, M. L.; Kadau, D.; Herrmann, H. J.; Pratsinis, S. E.; J. Aerosol Sci. 2012, 46, 7.

18. Chen, N.; Song, C.; Lv, G.; Song, J.; Gao, J.; Zhang, Z.; Combust. Flame 2015, 162, 4649.

19. Park, K.; Kittelson, D. B.; McMurry, P. H.; Aerosol Sci. Technol. 2004, 38, 881.

20. China, S.; Salvatori, N.; Mazzoleni, C.; Environ. Sci. Technol. 2014, 48, 3128.

21. Chung, A.; Lall, A. A.; Paulson, S. E.; Atmos. Environ. 2008, $42,2129$.

22. Neer, A.; Koylu, U. O.; Combust. Flame 2006, 146, 142.

23. Ajtai, T.; Pinter, M.; Utry, N.; Kiss-Albert, G.; Gulyas, G.; Pusztai, P.; Puskas, R.; Bereczky, A.; Szabados, Gy.; Szabo, G.; Konya, Z.; Bozoki, Z.; Atmos. Environ. 2016, 134, 109.

24. Barone, T. L.; Zhu, Y.; Atmos. Environ. 2008, 42, 6749.

25. Xiong, C.; Friedlander, S. K.; Proc. Natl. Acad. Sci. USA 2001, 98, 11851.

26. Salamanca, M.; Mondragon, F.; Agudelo, J. R.; Benjumea, P.; Santamaria, A.; Combust. Flame 2012, 159, 1100.

27. Karavalakis, G.; Stournas, S.; Bakeas, E.; Atmos. Environ. 2009, 43, 1745.

28. Ballesteros, R.; Hérnandez, J. J.; Lyons, L. L.; Atmos. Environ. 2010, 44, 930.

29. Lapuerta, M.; Martos, F. J.; Herreros, J. M.; J. Aerosol Sci. 2007, 38, 455.

30. Agarwal, A. K.; Gupta, T.; Kothari, A.; Renewable Sustainable Energy Rev. 2011, 15, 3278.

31. Traviss, N.; Li, M.; Lombard, M.; Thelen, B. A.; Palmer, B. C.; Poynter, M. E.; Mossman, B. T.; Holmen, B. A.; Fugakawa, B. T.; Air .Qual. Atmos. Health 2014, 7, 59.

32. Betha, R.; Balabramanian, R.; Engling, G. In Biodiesel Feedstocks, Production and Applications; Fang, Z., ed.; Intech, 2013, ch. 17, DOI: 10.5772/53476.

33. Guarieiro, L. L. N.; Pereira, P. A. D.; Torres, E. A.; da Rocha, G. O.; de Andrade, J. B.; Atmos. Environ. 2008, 42, 8211.

34. Guarieiro, L. L. N.; de Souza, A. F.; Torres, E. A.; de Andrade, J. B.; Atmos. Environ. 2009, 43, 2754.

35. Guarieiro, L. L. N; Guarieiro, A. L. N. In Biofuel - Economy, Environment and Sustainability; Fang, Z., ed.; Intech, 2013, ch. 14, DOI: $10.5772 / 52513$. 
36. Kim, J.; Jang, J.; Lee, K.; Lee, S.; Oh, S.; Int. J. Automot. Technol. 2014, 15, 183.

37. Birch, M. E.; Cary, R. A.; Aerosol Sci. Technol. 1996, 25, 221.

38. Brasil, A. M.; Farias, T. L.; Carvalho, M. G.; J. Aerosol Sci. 1999, 30, 1379.

39. Wosniak, M.; Onofri, F. R. A.; Barbosa, S.; Yon, J.; Mroczka, J.; J. Aerosol Sci. 2012, 47, 12.

40. Brasil, A. M.; Farias, T. L.; Carvalho, M. G.; Koylu, U. O.; Aerosol Sci. 2001, 32, 489.

41. Koylu, U. O.; McEnally, C. S.; Rosner, D. E.; Pfefferle, L. D.; Combust. Flame 1997, 110, 494.

42. Schaefer, D. W.; MRS Bull. 1988, 13, 22.

43. Peng, C.-Y.; Lan, C.-H.; Dai, Y. T.; Chemosphere 2006, 65, 2054.

44. Mkoma, S. L.; da Rocha, G. O.; Regis, A. C. D.; Domingos, J. S. S.; Santos, J. V. S.; de Andrade, S. J.; Carvalho, L. S.; de Andrade, J. B.; Fuel 2014, 115, 109.
45. da Silva, T. O.; Pereira, P. A. P.; J. Agric. Food Chem. 2008, 56, 3129.

46. Jung, Y.; Bae, C.; Fuel 2015, 161, 312.

47. Seong, H.; Lee, K.; Choi, S.; Adams, C.; Foster, D.; SAE Tech. Pap. Ser. 2012, No. 2012-01-0441.

48. Lu, T.; Cheung, C. S.; Huang, Z.; J. Aerosol Sci. 2012, 47, 27.

49. Chandler, M. F.; Teng, Y.; Koylu, U. O.; Proc. Combust. Inst. 2007, 31, 2971.

50. Lee, K. O.; Cole, R.; Sekar, R.; Choi, M. Y.; Kang, J. S.; Ba, C. S.; Shin, H. D.; Proc. Combust. Inst. 2002, $29,647$.

51. Lee, K.; Zhu, J.; Ciatti, S.; Yozgatligil, A.; Choi, M. Y.; SAE Tech. Pap. Ser. 2003, No. 2003-01-3169.

Submitted: August 11, 2016

Published online: November 24, 2016 